\title{
Conflictos normativos, jurídicos y sociales del ciclo extractivo en clave del sistema internacional, regional y nacional de Colombia*
}

Legal and social conflicts of the extractive cycle based on the international, regional and Colombia's national system

Conflitos normativos, jurídicos e sociais do ciclo de extração segundo o sistema internacional, regional e nacional da Colômbia

Conflits normatifs, juridiques et sociaux du cycle de l'extraction, clé du système international, régional et national de Colombie

\section{Jaime Cubides Cárdenas}

Magíster en Derecho

Miembro del Grupo Interdisciplinario de Estudios sobre Religión, Sociedad y Política Universidad de San Buenaventura, Bogotá - Colombia.

Correo electrónico: jaimecubides@gmail.com

\footnotetext{
Artículo que presenta en conjunto los resultados de los proyectos de investigación: (i) "Desafíos para la seguridad y defensa nacional de Colombia - Fase III", que hace parte de la línea de investigación "Políticas y modelos de seguridad y defensa" del grupo de investigación Centro de Gravedad, reconocido y categorizado en (A) por Colciencias, registrado con el código COL0104976 y, adscrito y financiado por la Escuela Superior de Guerra de la República de Colombia, y (ii) "Medidas estatales para la Paz Colombiana: El rol del Ejército Nacional en escenarios de pos-acuerdo y justicia transicional", que hace parte de la línea de investigación: "Teoría del Derecho y Administración de Justicia" del grupo de investigación "Grupo Interdisciplinario de Estudios sobre Religión, Sociedad y Política (GIERSP)", reconocido y categorizado en (A) por COLCIENCIAS registrado con el código COL0046166 vinculado a la Facultad de Ciencias Jurídicas y Políticas, adscrito y financiado por la Universidad de San Buenaventura, sede Bogotá..
} 


\title{
Juan David González Agudelo \\ Magíster en Derechos Humanos y Derecho Internacional de los Conflictos Armados Escuela Superior de Guerra, Bogotá - Colombia. \\ Correo electrónico: jdgagudelo@gmail.co
}

\author{
Juan Carlos Hoyos Rojas \\ Magister en Derecho Público, Miembro del Grupo de Masa Crítica \\ Escuela Superior de Guerra, Bogotá - Colombia \\ Correo electrónico: juan.hoyos@esdegue.edu.co
}

\section{Resumen}

El presente artículo gira en torno a los conflictos normativos y jurídicos en el ciclo extractivo, a partir del marco normativo en los sistemas internacional, regional y colombiano. Para lo anterior, se sigue una metodología hermenéutica cualitativa con un enfoque sistémico, desplegada en tres ejes temáticos: el primero ilustra la consulta previa y consentimiento en la prospección y exploración; el segundo analiza la propiedad comunal un conflicto complejo en la construcción y transformación extractiva; el tercero se ocupa del ordenamiento jurídico colombiano en relación con la explotación y beneficio en la transformación extractiva. Se concluye que, en Colombia, son dos los mecanismos usados tradicionalmente; el primero, la acción pública de inconstitucionalidad; y el segundo, la acción de tutela. Asimismo, el marco normativo y las reglas jurisprudenciales fijadas por la Corte Constitucional en el tema de los recursos naturales no han sido suficientemente asimiladas por parte de las autoridades estatales, por lo tanto es aún un reto que los acuerdos o la concertación estén desprovistos de arbitrariedad y de autoritarismo.

\section{Palabras clave}

Recursos naturales, minería, consulta previa, propiedad comunal, medio ambiente.

\section{Cómo citar este artículo:}

Cubides, J., González, J. y Hoyos, J. (2019). Conflictos normativos, jurídicos y sociales del ciclo extractivo en clave del sistema internacional, regional y nacional de Colombia. Revista de la Facultad de Derecho y Ciencias Políticas, 49(130), pp. 146-174. in press. doi: http://dx.doi.org/10.18566/ rfdcp.v49n130.a7

Recibido: 22 de abril de 2019.

Aprobado: 15 de mayo de 2019. 


\section{Abstract}

The present paper addresses the legal conflicts in the extractive cycle, based on the legal framework of the international, regional and Colombian system. In order to achieve this, a hermeneutic methodology of qualitative type is followed with a systemic focus, developed into three thematic axes. The first one illustrates the consulta previa (prior consultation) and consent in prospecting and exploration. The second analyses communal property, a complex conflict in the extractive construction and transformation. The third addresses Colombia's law in relation to the exploitation and benefit in the extractive transformation. It is concluded that, in Colombia, there are two traditionally used mechanisms, the first one being the acción pública de inconstitucionalidad (public action of unconstitutionality) and the second one, the acción de tutela (protective action of constitutional rights ). Likewise, the legal framework and the caselaw established by the Corte Cosntitucional regarding natural resources has not been sufficiently assimilated by the state authorities. Therefore, the challenge that agreements and concertation should be devoid of arbitrariness and authoritarianism remains.

\section{Key Words}

Natural resources; Mining; Prior consultation; Communal property; Environment.

\section{Resumo}

Este artigo pesquisa os conflitos normativos e jurídicos no ciclo de extração, segundo as normas do sistema internacional, regional e colombiano. Em vista disso, considera-se uma metodologia hermenêutica qualitativa desde uma perspectiva sistêmica, que se desenvolve a partir de três eixos temáticos: o primeiro ilustra a consulta previa e o consentimento na pesquisa e exploração; o segundo analisa a propriedade comunal, um conflito complexo na construção e transformação da extração, o terceiro se ocupa da classificação jurídica colombiana ao respeito da exploração e em proveito da transformação extrativa. Concluise que em Colômbia, dois são os mecanismos tradicionais: o primeiro a ação pública da inconstitucionalidade e o segundo a ação de tutela. Igualmente, o sistema normativo e as regras jurisprudenciais da Corte Constitucional, ao respeito dos recursos naturais, não têm sido apropriadas pelas autoridades estatais; portanto, ainda existe o desafio de liberar os acordos e a concertação da injustiça e do autoritarismo.

\section{Palavras chaves}

Recursos naturais, mineração, consulta prévia, propriedade comunal e meio ambiente 


\section{Résumé}

Cet article développe les conflits normatifs et juridiques du cycle de l'extraction, à partir du cadre normatif du système international, régional et colombien. Pour cela, on utilise une méthodologie herméneutique de type qualitatif avec un angle systématique, développée en trois axes thématiques. Le premier illustre la consultation préalable et le consentement concernant la prospection et l'exploration, le second analyse la propriété collective, un conflit complexe dans la construction et la transformation extractive, le troisième s'occupe du système juridique colombien en matière d'exploitation et de bénéfices de la transformation extractive. Cet article conclut qu'en Colombie deux mécanismes sont utilisés traditionnellement : le premier étant l'action publique d'inconstitutionnalité et le second l'action de tutelle. Aussi, le cadre normatif et les règles de jurisprudence fixées par la Cour constitutionnelle concernant les ressources naturelles nont pas été suffisamment assimilés par les autorités étatiques. Par conséquent, le défi reste d'éliminer l'arbitraire et l'autoritarisme des accords et de la concertation.

\section{Mots-clés}

Ressources naturelles, exploitation minière, consultation préalable, propriété collective, environnement.

\section{Introducción}

La extracción de recursos naturales desempeña un rol cada vez más transcendental para la economía de numerosos países, porque la exportación de minerales ha contribuido al aumento de los índices de crecimiento, razón por la cual algunas naciones que en el pasado no contaban con un sector significativo de extracción de minerales, han despertado ahora su interés, pues buscan aprovechar los altos precios del oro, el petróleo y el carbón (Slack, 2011). Particularmente, durante la última década, el número y la intensidad de los conflictos sociales han aumentado considerablemente y han amenazado la gobernabilidad democrática y la estabilidad de varios países. Si bien las causas de estos conflictos varían, una parte significativa se asocia con el manejo y la explotación de los recursos naturales durante y después del ciclo minero (Fundación para el Debido Proceso \& Oxfam, 2011).

Esta expansión, que ha sido facilitada por diversos mecanismos como privatizaciones, exenciones tributarias y flexibilización del licenciamiento 
ambiental, además de una ausencia de fiscalización y supervisión estatal en la debida diligencia del Estado en la protección de los derechos humanos (Fundación para el Debido Proceso \& Oxfam, 2015). Esto ilustra una tensión que enfrentan dos maneras de entender el desarrollo: por un lado, la de los Estados, que alientan la inversión privada, como expresión de su deber de promover el desarrollo, tal como se encuentra consagrado en sus constituciones; y por otro, la visión de los pueblos indígenas o los tribales, de los campesinos, donde su derecho a usar y gozar de sus tierras está protegido de acuerdo con su cosmovisión y bajo la protección constitucional de cada nación (Fundación para el Debido Proceso \& Oxfam, 2011).

En este sentido, los conflictos normativos y jurídicos del sector extractivo en la explotación subterránea y a cielo abierto, tiene su origen en la rama del derecho internacional de los derechos humanos, también conocida como derecho internacional de los pueblos indígenas, cuyo surgimiento es relativamente de reciente (Galvis y Ramírez, 2013). Pues, si bien el Convenio 169 de la Organización Internacional del Trabajo (OIT) fue adoptado en la segunda mitad del siglo XX, no es sino hasta el siglo XXI, concretamente en el 2001, que en el contexto internacional se establece la relatoría especial de las Naciones Unidas sobre la situación de los derechos humanos y las libertades fundamentales de los indígenas (Galvis y Ramírez, 2013).

De aquí que la explotación de los recursos naturales se efectúa, en algunos casos, en territorios ocupados históricamente por pueblos indígenas y comunidades afrodescendientes, ya que estas son áreas que tradicionalmente albergan una gran cantidad de recursos (CIDH, 2015).

A su vez, dado el disperso marco normativo en los sistemas internacionales, regional y nacional de Colombia, los Estados receptores o los de origen del sector extractivo se deslindan de una adecuada planeación u organización. Motivo por el cual la problemática que se pretende estudiar en el presente texto está orientada por la siguiente pregunta: ¿qué sucede con las problemáticas normativas, jurídicas y sociales fundamentalmente durante el ciclo minero, con especial atención en las explotaciones subterránea y a cielo abierto? 


\section{Consulta previa y consentimiento en la prospección y exploración}

\section{Parámetros internacionales}

El derecho a la consulta y consentimiento previo, libre e informado de los pueblos indígenas ha tenido mayor desarrollo jurídico y político en América Latina. Ello no resulta casual, teniendo en cuenta que la población indígena en la región equivale a más del 8 \% del total de la población total y alcanza los 45 millones de personas, quienes, se podría afirmar, pertenecen a más de 800 pueblos distintos (Fundación para el Debido Proceso \& Oxfam, 2015). En virtud de este argumento las disposiciones normativas establecidas en el Convenio 169 de la OIT, así como en la Declaración de las Naciones Unidas sobre los derechos de los pueblos indígenas, prevén la consulta previa como una forma específica de participación de los pueblos indígenas - concretamente en los artículos 6 del Convenio, y 19 y 32 de la declaración- (Galvis y Ramírez, 2013).

Asimismo, varios ordenamientos jurídicos latinoamericanos han reconocido el derecho a la consulta previa como una forma especial de participación, orientada a garantizar los derechos de los pueblos indígenas en el marco de los procesos de toma de decisiones estatales que los afecten (Galvis y Ramírez, 2013). El relator especial de Naciones Unidas, al respecto, ha mencionado que: "El deber de celebrar consultas se deriva del derecho primordial de los pueblos indígenas a la libre determinación y de los principios conexos de democracia y soberanía popular"1.

No obstante, esta afirmación plantea dos dilemas: por un lado, los pueblos indígenas consideran que el consentimiento libre, previo e informado es un requisito indispensable de la consulta y una manifestación del ejercicio de su derecho a la libre determinación, definido en la normativa internacional de derechos humanos. Y, por otro, los Estados quieren que las normas que regulen el derecho a la consulta señalen expresamente la inexistencia de un "derecho de veto" de las comunidades sobre las decisiones adoptadas por las autoridades (Fundación para el Debido Proceso \& Oxfam, 2011).

1 Véase: Naciones Unidas, Asamblea General, informe del relator especial sobre la situación de los derechos humanos y las libertades fundamentales de los indígenas, James Anaya, Doc. ONU A/66/288, de agosto de 2011, párr. 79. 
Esta consideración, no quiere decir que, ante la ausencia de un derecho de veto de los pueblos indígenas, el Estado tenga la libertad o la facultad de tomar decisiones que afecten sus derechos. Esto, al entender que el derecho a la consulta previa no les otorga tampoco a los pueblos indígenas el poder unilateral de vetar las decisiones estatales sin una justificación (Fundación para el Debido Proceso \& Oxfam, 2011).

Como es natural los procesos de consulta, se debe propugnar por un entendimiento mutuo y se deben tomar decisiones consensuadas cada vez que se quieran realizar proyectos en territorios indígenas o aprobar leyes o medidas administrativas que podrían afectarlos (Fundación para el Debido Proceso \& Oxfam, 2011). De lo que se trata es de aplicar el principio de buena fe en todo proceso de consulta - especialmente en las fases de prospección y exploración-, lo cual implica un diálogo permanente en el que todas las partes involucradas estén dispuestas a escuchar y a ceder en sus posiciones mientras defienden sus legítimos intereses (Fundación para el Debido Proceso \& Oxfam, 2011).

Este principio se relaciona también con la necesidad de que la consulta no se agote en un mero trámite formal, sino que debe concebirse como "un verdadero instrumento de participación” (CIDH, 2015). Esto, si el Estado ya contara con una decisión predeterminada antes del proceso de consulta. La participación política como prerrequisito para la realización de aspectos básicos de la inclusión de grupos en condiciones de desigualdad limitaría la autodeterminación y el desarrollo de los pueblos indígenas dentro de un Estado plural y democrático ${ }^{2}$.

De ahí que la consulta previa sea el primer requisito en la participación efectiva de los pueblos indígenas o los tribales y campesinos, pues solo de la adecuada intervención en los procesos de diseño, ejecución, evaluación, desarrollo, inversión, exploración o extracción las costumbres y tradiciones de los territorios ancestrales podrán conservarse (CIDH, 2015). Del mismo modo, la consulta informada, tal como ha sido señalada por la Corte IDH en el caso del pueblo Saramaka vs. Surinam (2007) el Estado debe asegurarse de que los pueblos: "tengan conocimiento de los posibles riesgos, incluido los riesgos ambientales y de salubridad, a fin de que acepten el plan de desarrollo o inversión propuesto con conocimiento y de forma voluntaria” (párr. 133).

2 Véase: observación general No. 25, comentarios generales adoptados por el Comité de los Derechos Humanos, Artículo 25 - la participación en los asuntos públicos y el derecho de voto, $57 .{ }^{\circ}$ período de sesiones, U.N. Doc. HRI/GEN/1/Rev.7 at 194 (1996), párr. 113. 
En otras palabras, la consulta siempre debe ser libre, es decir, requiere la ausencia de cualquier tipo de coerción por parte del Estado o terceros que actúan con su autorización o aquiescencia (CIDH, 2015). En esta misma línea, la Corte IDH ha indicado en el caso pueblo indígena Kichwa de Sarayaku vs. Ecuador (2012), que la firma de acuerdos o convenios entre los Estados y las empresas extractivas con el objetivo de prestar de seguridad privada de parte de las fuerzas armadas o policía nacional, no favorece un clima de confianza y respeto mutuo para alcanzar consensos entre las partes.

Cuando la consulta y el consentimiento previo, libre e informado de los pueblos indígenas no fuese posible, el Estado debe respetar la decisión de la comunidad y suspender el proyecto ${ }^{3}$, ya que si continuara con los proyectos se configura una restricción ilegítima del derecho a la propiedad comunitaria de los pueblos indígenas y tribales (Fundación para el Debido Proceso \& Oxfam, 2011).

Los casos hasta ahora identificados y estudiados en el ámbito internacional evidencian los siguientes parámetros globales para explotar los recursos naturales por parte del sector extractivo, es decir, debe existir la consulta previa y el consentimiento en la prospección y exploración, cuando:

i) el proyecto implique traslado de los pueblos indígenas de sus tierras tradicionales (tribales y campesinos) ${ }^{4}$;

ii) el proyecto implique el almacenamiento o eliminación de materiales peligrosos en sus territorios (indígenas, tribales y campesinos) ${ }^{5}$;

iii) se trata de planes de desarrollo o de inversión a gran escala, que pudieran tener un impacto mayor en los territorios indígenas (tribales y campesinos) ${ }^{6}$;

iv) se trata de actividades de extracción de recursos naturales en territorios indígenas (tribales y campesinos) que tengan impactos sociales, culturales y ambientales significativos ${ }^{7}$.

3 Ver, por ejemplo: MC 260-07 a favor de las comunidades del pueblo Maya (Sipakapense y Mam) de los municipios de Sipacapa y San Miguel Ixtahuacán en el departamento de San Marcos, Guatemala. Cfr. Declaración de Naciones Unidas sobre los derechos de los pueblos indígenas, Artículo 10. Ibíd. Artículo 29.2.

Cfr. Corte IDH, caso del pueblo Saramaka Vs. Surinam, párr. 133.

Véase: declaración pública del relator especial sobre los derechos humanos y libertades fundamentales de los indígenas, James Anaya, sobre la "ley del derecho a la consulta previa a los pueblos indígenas u originarios reconocido en el Convenio N ${ }^{\circ} .169$ de la Organización Internacional de Trabajo" aprobada por el Congreso de la República del Perú, el 7 de julio de 2010, pág. 3. 
No obstante, a pesar de existir parámetros internacionales ${ }^{8}$ para explotar los recursos naturales por parte del sector extractivo, la dinámica global vigente denota que no hay una uniformidad en torno a dichos criterios para explotar los recursos naturales por parte del sector extractivo - especialmente en la explotación subterránea-. De manera que países como Bolivia, Brasil, Chile, Colombia, Guatemala, Perú y Ecuador no tienen desarrollos jurídicos ni normativos fuertes 0 vinculantes en esta materia.

De ahí que los principales parámetros internacionales solo hagan referencia a la minería hidrocarburífera (cielo abierto). Bolivia, especialmente, consagra el derecho a la consulta previa y consentimiento en la prospección y exploración. Reconocimiento legal amplio en materia de actividades hidrocarburíferas y avance normativo que han sido acogidos con beneplácito por la OIT, la CIDH $^{9}$ y la ONU (Fundación para el Debido Proceso \& Oxfam, 2011). Como ejemplo se puede resaltar el proceso desarrollado en el territorio indígena de Charagua Norte e Isoso, el cual se realizó en coordinación con el Ministerio de Hidrocarburos y Energía, y cumplió con los objetivos y resultados esperados en todas sus etapas y fases, bajo los mecanismos e instituciones propios del pueblo indígena guaraní (Fundación para el Debido Proceso \& Oxfam, 2011). Aunque en otros casos la actividad hidrocarburífera que se ha desarrollado principalmente en el chaco boliviano tiene una larga data y ha ocasionado una serie afectaciones negativas con pasivos ambientales de consideración en la región (CIDH, 2015).

En últimas, obtener el consentimiento de las comunidades indígenas 0 afrodescendientes no es un requisito que el Estado deba necesariamente agotar, en estos casos, para poder avanzar con el proyecto o la medida legislativa 0 administrativa. Las salvaguardas que se exigenalEstado, son lashabercumplido con todos los requisitos procedimentales y sustanciales de la consulta previa, para asegurar que el proyecto no tendrá un impacto social, cultural o ambiental significativo sobre el pueblo indígena, tribales y campesinos afectados y que se tomarán medidas para salvaguardar todos sus derechos, inclusive su derecho a sentar sus propias prioridades para el desarrollo (Fundación para el Debido Proceso \& Oxfam, 2011). Conjuntamente, la CIDH ha reiterado que el

8 La jurisprudencia de la Corte Interamericana de Derechos Humanos ha sido reconocida por los tribunales internacionales como una de las más activistas en materia de protección (Vivas y Cubides, 2012).

9 Encargada de promover el respeto de los derechos humanos. Desde 1965, la CIDH fue autorizada de modo expreso para recibir y procesar denuncias o peticiones sobre casos individuales en los que se alegaran violaciones a los DD.HH. (Cubides y Martínez, 2015,p.96). 
acceso a la información es un prerrequisito para la participación pública en la toma de decisiones y para que los individuos puedan seguir de cerca y responder a las acciones del sector público y del privado en lo referente al medio ambiente (CIDH, 1997).

\section{La propiedad comunal, un conflicto complejo en la construcción y transformación extractiva}

\section{El sistema interamericano de derechos humanos}

El derecho internacional, en relación con los derechos humanos, ha construido un concepto de propiedad diferente para los pueblos indígenas y tribales, fundado en el reconocimiento del carácter colectivo de la misma y de la estrecha vinculación de los pueblos indígenas con sus tierras tradicionales y cultura, a más de integrar los elementos incorporales (Fundación para el Debido Proceso \& Oxfam, 2011). Pues solo de salvaguardar este derecho, los Estados garantizan la supervivencia social, cultural y económica de los pueblos indígenas y tribales (Comunidad Indígena Xákmok Kásek vs. Paraguay, 2010). Esto, dado que la continua utilización de sistemas colectivos tradicionales de control y uso del territorio es esencial en muchas circunstancias para el bienestar individual y colectivo y, en efecto, para la supervivencia de los pueblos indígenas (CIDH, 2002, párr. 128). Esto especialmente, porque el uso y goce de la tierra y de sus recursos son componentes integrales de la supervivencia física y cultural de las comunidades indígenas y de la efectiva realización de sus derechos humanos en términos más generales (CIDH, 2004, párr. 114).

De aquí, que el derecho a la propiedad comunal en el sistema interamericano de derechos humanos no esté en ninguno de sus instrumentos textualmente, pero sí reconozca el derecho de los pueblos indígenas y tribales sobre sus territorios tradicionales. Toma como base el derecho a la propiedad privada, la cual está regulada en los artículos 21.1 y 21.2 de la Convención Americana de Derechos Humanos — en adelante CADH — . Donde la Corte IDH entiende que para los indígenas [o los tribales] existe una tradición comunal sobre la propiedad colectiva, pues consideran que este dominio no se centra en un solo individuo, sino en la comunidad entera (Comunidad Indígena Xákmok Kásek vs. Paraguay, 2010, párr. 86). 
Es por dichos motivos que el derecho a la propiedad privada es un derecho humano cuya vulneración es de especial gravedad (Caso de las Masacres de Ituango vs. Colombia, párr. 181) Por ello, respecto a la propiedad se ha establecido que es:

el requisito según el cual las leyes han de ser dictadas por razones de interés general, lo cual significa que deben haber sido adoptadas en función del "bien común” (Art. 32.2 CADH), concepto que ha de interpretarse como elemento integrante del orden público del Estado democrático, cuyo fin principal es "la protección de los derechos esenciales del hombre y la creación de circunstancias que le permitan progresar espiritual y materialmente y alcanzar la felicidad." (Declaración Americana de los Derechos y Deberes del Hombre, párr. 1) ${ }^{10}$

Finalmente, la corte resalta que, tanto la propiedad privada de los particulares como la propiedad comunitaria de los miembros de las comunidades indígenas [afros y particulares (campesinos)] tienen la protección convencional que les otorga el Artículo 21 de la Convención Americana desde el desarrollo contenido en el caso de la comunidad indígena Yakye Axa vs. Paraguay, 2005.

Es prudente advertir que la propiedad comunal es un conflicto complejo en la construcción y transformación extractiva, especialmente en cuanto a estándares del sistema interamericano de derechos humanos; pues una comunidad es tribal, respecto a lo establecido por el Convenio 169 de 1989 de la Organización Internacional del Trabajo, en su Artículo 1.a. Motivo por el cual la corte ha considerado que una comunidad tribal tiene características sociales, culturales y económicas diferentes de otras secciones de la comunidad nacional, particularmente gracias a la relación especial existente con sus territorios ancestrales y porque se regulan ellos mismos, al menos en forma parcial, a través de sus propias normas, costumbres y tradiciones (caso del pueblo Saramaka vs. Surinam, 2007, párr. 84).

De la misma forma, el Convenio 169, Artículo 1.b, reconoce a los pueblos indígenas. Este apartado fue desarrollado por Corte IDH, la cual considera que la identificación de una comunidad indígena corresponde a un hecho histórico social que hace parte de su autonomía (comunidad indígena Xákmok Kásek vs. Paraguay, 2010, párr. 37). Consideración que igualmente ha sido destacada

10 Véase: Corte IDH. La expresión "leyes" en el Artículo 30 de la Convención Americana sobre Derechos Humanos. Opinión consultiva OC-6/86 del 9 de mayo de 1986. Serie A N. ${ }^{\circ}$ 6., Párr. 29. 
por la CIDH, ya que lo principal para la determinación del ser indígena, tanto individual como colectivamente, es el criterio de autoidentificación (CIDH, 2007, párr. 217).

Esto nos circunscribe a la construcción y transformación extractivas, pues el derecho a la propiedad comunal se deriva, en primer lugar, del uso y ocupación tradicionales de la tierra y recursos necesarios para la subsistencia física y cultural de los pueblos indígenas y tribales y de sus miembros y, en segundo lugar, a los sistemas consuetudinarios de propiedad que de allí se desprenden. Según ha explicado la comisión, los pueblos indígenas y tribales tienen, por ende, derechos de propiedad, posesión y dominio respecto de las tierras, territorios y recursos que han ocupado históricamente (CIDH, 2004, párr. 115).

Al mismo tiempo, los casos contenciosos de la Corte Interamericana han ido diseñando el marco jurídico internacional para resolver los complejos conflictos que surgen entre Estados y comunidades indígenas o tribales por la falta de reconocimiento — de iure y de facto- de su derecho a la propiedad. Como ejemplo se puede resaltar el caso de la comunidad Mayagna (Sumo) Awas Tingni vs. Nicaragua. En este, la corte resolvió que los conflictos de derechos ocasionados por la falta de delimitación y demarcación de territorio eran daños inmateriales que debían ser reparados por vía sustitutiva mediante una indemnización pecuniaria. Ya que la protección del derecho a la propiedad comunitaria de los pueblos indígenas debe salvaguardar también la estrecha vinculación [que estos tienen] sobre sus territorios tradicionales, y los recursos naturales ligados a su cultura que ahí se encuentren, así como los elementos inmateriales que se desprendan de ellos (caso pueblo indígena Kichwa de Sarayaku vs. Ecuador, 2012, párr.145).

No obstante, en el ámbito internacional, los tribunales han decidido que, en los casos en que se produjeron graves violaciones del derecho a la propiedad comunal al explotar recursos naturales renovables, las comunidades protegidas habían venido usando tradicionalmente estos territorios, que son necesarios para su propia supervivencia, para el desarrollo y continuidad de su estilo de vida, como es el caso de los recursos forestales. Evidentemente, los pueblos indígenas [o los tribales (campesinos)] tienen derechos sobre estos recursos y el Estado tiene el deber de consultar previamente y buscar el consentimiento (caso del pueblo Saramaka vs. Surinam, 2008, párr. 122).

De manera que los órganos del sistema interamericano le han prestado una particular atención al derecho de los pueblos indígenas y tribales a la 
propiedad comunal, como un derecho en sí mismo en tanto es una garantía del disfrute efectivo de otros derechos básicos, aplicables a la protección del resto de las garantías del derecho de propiedad comunal indígena [o los tribales (campesinos)] (CIDH, 2009). Es por esto que, cuando hay extracción ilegal de recursos naturales en sus territorios, no es necesario que estas comunidades cuenten con un título formal de propiedad para que puedan acceder a los tribunales para exigir la garantía de este derecho, incluyendo la reparación por daños y perjuicios (CIDH, 2009, párr. 392).

De cualquier modo, la cuestión de la titulación no deja de constituir el eje central en la Corte Interamericana, la cual, en el caso de la comunidad Mayagna (Sumo) Awas Tingni vs. Nicaragua, 2001

sostuvo explícitamente que el reconocimiento de los derechos de propiedad comunal indígena debe garantizarse a través del otorgamiento de un título de propiedad formal u otra forma similar de reconocimiento estatal, que otorgue seguridad jurídica a la tenencia indígena [o los tribales] de la tierra frente a la acción de terceros. (párr. 3).

Sumado a lo anterior, mediante una interpretación evolutiva de los instrumentos internacionales de protección de derechos humanos, la corte ha tomado en cuenta las normas de interpretación aplicables. Es decir, que esto sucede de conformidad con el Artículo 29.b de la convención — que prohíbe una interpretación restrictiva de los derechos-. El derecho internacional en la rama de los derechos humanos protege los derechos de los pueblos indígenas, y tiene, cada vez, más influencia en las decisiones de los jueces nacionales, quienes han incorporado en los ordenamientos jurídicos internos las normas y la jurisprudencia internacionales por medio del control difuso de convencionalidad (Galvis \& Ramírez, 2013).

Quizás lo más importante es que, en poco tiempo, se ha producido un importante cuerpo de decisiones que protegen los derechos de los pueblos indígenas, tribales y campesinos. En particular, en lo atinente a la jurisprudencia interamericana y a los países andinos como Colombia, Bolivia, Perú y Ecuador, los cuales, a su vez, han tomado como referente los pronunciamientos del relator especial de las Naciones Unidas sobre la situación de los derechos humanos y las libertades fundamentales de los indígenas (Galvis \& Ramírez, 2013). 
De esta manera, las características especiales de la propiedad comunal requieren del Estado reales esfuerzos para superar la exclusión histórica de los pueblos indígenas y las comunidades rurales o los tribales, pues los conflictos más complejos se dan durante la construcción y transformación extractiva de los recursos naturales, donde acontece una superposición histórica de derechos de terceros sobre los derechos de propiedad comunal. Prevalencia dada, en muchos casos, por el Estado a los terceros, compromiso surtido de la visión estatal de progreso y desarrollo (Fundación para el Debido Proceso \& Oxfam, 2011).

\section{Ordenamiento jurídico colombiano en relación con la explotación y beneficio en la transformación extractiva}

\section{Marco normativo disperso}

Origen y fundamento de los derechos sobre la tierra

Los derechos sobre la tierra, especialmente en lo referente a resguardos indígenas, junto con las encomiendas y las mitas, son instituciones de origen colonial en América Latina. En Colombia, los resguardos indígenas se entienden como una forma de propiedad colectiva de la tierra y han sido definidos como:

una institución legal y sociopolítica de carácter especial, conformada por una comunidad o parcialidad indígena que, con un título de propiedad comunitaria, posee su territorio y se rige para el manejo de este y de su vida interna por una organización ajustada al fuero indígena o a sus pautas y tradiciones culturales. (Decreto 2001 de 1998, artículo 2).

Asimismo, los artículos 63 y 329 de la Constitución Política de Colombia, garantizan que las tierras tradicionales de los pueblos indígenas sean de propiedad colectiva, inalienable e inembargable. Además, el Artículo 246 de la Carta Magna dispone que los territorios indígenas tengan su propio gobierno y autoriza una conformación que les garantiza una jurisdicción indígena con normas tradicionales. 
No obstante, a pesar de existir el mandato constitucional hay una falta de consenso en el ordenamiento jurídico, lo que ha ocasionado una inseguridad jurídica, particularmente, a luz del Artículo 332 de la Constitución, el cual establece que: "el Estado es propietario del subsuelo y de los recursos naturales no renovables, sin perjuicio de los derechos adquiridos y perfeccionados con arreglo a las leyes preexistentes".

En este sentido, los citados derechos comparten las prerrogativas inherentes de la propiedad privada, las cuales han sido reconocidas por la propia Corte Constitucional, en Sentencia de Unificación 510 de 1998, la cual indica lo siguiente:

La Corte no ha dudado en reconocer, con base en las declaraciones constitucionales e internacionales respectivas, que la propiedad colectiva que las comunidades indígenas ejercen sobre sus resguardos y territorios tiene el carácter de derecho fundamental, no solo porque tales territorios constituyen su principal medio de subsistencia, sino, también, porque forman parte de su cosmovisión y religiosidad. En tanto propietarias de sus territorios, las comunidades indígenas son titulares de todas las prerrogativas que el Artículo 669 del Código Civil otorga a los titulares del derecho de propiedad, lo cual apareja el deber de los terceros de respetar el anotado derecho. [...]

De igual manera, la Corte Constitucional ha enfatizado que el concepto de territorio no se restringe a la ubicación geográfica de una comunidad o un resguardo indígena, sino que se asocia al concepto de ámbito cultural de la comunidad. Al respecto, en la Sentencia T-617 de 2010, se explicó:

[...] el factor territorial debe entenderse en armonía con la idea de ámbito territorial de la comunidad, definida por la Corte Constitucional en otras providencias, de acuerdo con el cual el territorio es el lugar en donde se desarrolla la vida social de la comunidad indígena.

En definitiva, el derecho a la propiedad colectiva es fundamental en tanto la tierra 0 el territorio colectivos se desprenden, en el orden interno del Artículo 329 superior, que le atribuye el carácter de propiedad colectiva al territorio de los resguardos, en armonía con el Artículo 58, que ordena proteger todas las formas de propiedad; y el Artículo 63 de la Constitución Política de Colombia, que les atribuye a los citados territorios las cualidades de inembargables, inalienables e imprescriptibles (Sentencia T-235 de 2011). 
En virtud de lo expuesto, las comunidades indígenas, de conformidad con reiterada jurisprudencia, son sujetos constitucionales de especial protección, en razón a la situación de marginamiento y discriminación a la que tradicionalmente han estado sometidas (Sentencia C-180 de 2005). Adicionalmente, con fundamento en el principio constitucional que reconoce el carácter pluriétnico y multicultural de la nación colombiana, en el Artículo 7 y en el Convenio 169 de la OIT (Ley 21 de 1991), la Corte Constitucional ha reconocido a las comunidades indígenas como sujetos colectivos, titulares del derecho a la diversidad e integridad étnica y cultural.

En síntesis, la Constitución colombiana les brinda a las comunidades étnicas una protección especial sobre las costumbres, la autonomía y el territorio, salvaguarda que no solo se extiende y termina en la norma. Desconocer dichas garantías pondría en peligro la identidad de los pueblos étnicos y llevaría a destruir la independencia que las caracteriza, con notorio daño para la conservación y adecuado desarrollo de sus culturas y creencias, ya que el principal desarrollo ha recaído sobre las comunidades indígenas (Sentencia T- 129 de 2011).

\section{Leyes dispersas en el ordenamiento jurídico colombiano}

En Colombia, la implementación del derecho a la consulta se ha dado a través de distintos cuerpos legales y mediante instrumentos jurídicos de rango infra legal, sin que exista hasta el momento una ley general. De ahí que la Constitución Política de Colombia establece el derecho a la participación en su Artículo 40; el derecho a un medio ambiente sano, en su Artículo 39, y la planificación estatal del manejo y aprovechamiento de los recursos naturales en el Artículo 80. No obstante, el derecho a la consulta previa no se menciona expresamente en el texto constitucional. Sin embargo, ha sido configurado bajo el derecho a la participación (Artículo 40) y teniendo en cuenta el Artículo 330, que dispone que la explotación de los recursos naturales en territorios indígenas se realice sin daño a la integridad cultural, social y económica de las comunidades indígenas.

De esta manera, el marco jurídico de Colombia ha estado caracterizado por una reglamentación inconclusa, a pesar de haberse ratificado el Convenio 169 de la OIT (Ley 21 de 1991) y la Declaración de Naciones Unidas sobre los Derechos de los Pueblos Indígenas. 
En este orden de ideas, cabe enunciar que en la Ley 99 de 1993 - Ley General Ambiental-, establece que la explotación de recursos naturales deberá hacerse previa consulta con los representantes de las comunidades indígenas y afrodescendientes. En ella, en el Artículo 76, sobre las comunidades indígenas y negras, se señala:

La explotación de los recursos naturales deberá hacerse sin desmedro de la integridad cultural, social y económica de las comunidades indígenas y de las negras tradicionales de acuerdo con la Ley 70 de 1993 y el Artículo 330 de la Constitución Nacional y las decisiones sobre la materia se tomarán, previa consulta a los representantes de tales comunidades (Ley 99 de 1993, artículo 76).

Es decir, cuando existiese un proyecto de explotación de recursos naturales, es necesario involucrar y consultar a las comunidades, pueblos y organizaciones indígenas [afros y particulares (campesinos)] para poder establecer que no se podrá otorgar ninguna licencia ambiental sin la realización de estudios de impacto económico, social y cultural, los cuales deberán ser completados con la participación de las comunidades, sus autoridades y sus organizaciones (Decreto 1397 de1996, artículo 7).

Sin embargo, en 1998 se adoptó el Decreto 1320, por el cual se reglamenta la consulta previa con las comunidades indígenas y negras para la explotación de los recursos naturales dentro de su territorio. No obstante, el procedimiento ha sido ampliamente criticado nacional e internacionalmente, puesto que tanto la Corte Constitucional como la Organización Internacional del Trabajo han concluido que dicho decreto es incompatible con el Convenio N. ${ }^{\circ} 169$ de la OIT y han solicitado a los ministerios competentes revisarlo y suspender su aplicación (Fundación para el Debido Proceso \& Oxfam, 2015).

En esta misma línea y con el propósito de subsanar las leyes y decretos expedidos con anterioridad, se ha expedido, por ejemplo, la directiva presidencial 001 de 2010, que busca la garantía del derecho a la consulta previa de los grupos étnicos nacionales, para establecer las acciones que requieren y los mecanismos para realizarla.

El Decreto 2893 de 2011 instauró, en el Ministerio del Interior, la dirección de consulta previa, la cual, de acuerdo con los artículos 13 y 14, tiene como función apoyar a la dirección de asuntos indígenas, rom, negras, 
afrocolombianas, raizales y palenqueras en la realización de los procesos de consulta previa que se efectúen en terreno, para que los proyectos de desarrollo tengan estrategias de corto y largo plazo para el manejo de crisis en el entorno de las comunidades y minorías étnicas. Adicionalmente, el Decreto 2613 de 2011 estableció la coordinación interinstitucional para la consulta previa.

Finalmente, la directiva presidencial 10 de 2013 estableció una guía para la realización de la consulta preliminar con comunidades étnicas, la cual busca articular la institucionalidad pública en torno a la dirección de consulta previa del Ministerio del Interior colombiano.

\section{El papel de la Corte Constitucional en el aprovechamiento de los recursos naturales}

En Colombia, existe un gran consenso en cuanto al papel clave de la Corte Constitucional para hacer efectivo el derecho a la consulta previa, puesto que, la jurisprudencia sobre la materia inició hacia mediados del siglo XX. En este sentido, la Corte determinó que, frente a la aprobación de medidas que afectaban directamente a los pueblos indígenas, tribales y campesinos, se vulnera sin duda alguna, el principio de participación de los grupos particularmente vulnerables en la nación, motivo por el cual exhorta al reconocimiento de la diversidad cultural y los compromisos internacionales adquiridos por el Estado.

Mandato constitucional particular, contenido en el parágrafo del Artículo 330 superior, el cual guarda una relación con el Artículo 15 del Convenio 169 de la OIT, donde se prevé un mandato particular en el mismo sentido, que le impone el deber al Estado de consultar con las comunidades toda medida relacionada con la utilización, administración y conservación de los recursos naturales, lo que incluye los recursos mineros.

En este sentido tanto la jurisprudencia constitucional colombiana como los tribunales internacionales de derechos humanos -especialmente la Corte IDH-, coinciden en que tales proyectos de explotación de recursos naturales tienen un importante grado de incidencia en la salvaguarda de la diversidad étnica y cultural de las comunidades. De ahí que la consulta previa deba suponer la adopción de relaciones de comunicación y entendimiento, signadas por el mutuo respeto y la buena fe, tendientes a buscar: 
[i] [...] [El] conocimiento pleno sobre los proyectos destinados a explorar o explotar los recursos naturales, los mecanismos, procedimientos y actividades requeridos para ponerlos en ejecución.

[ii] [El conocimiento] sobre la afectación o menoscabo de los elementos que constituyen la base de su cohesión social, cultural, económica y política [...].

[iii] La participación activa y efectiva en la toma de la decisión que deba adoptar la autoridad, la cual, en la medida de lo posible, debe ser acordada o concertada.

[iv] Que se manifieste, a través de sus representantes autorizados, su conformidad o inconformidad con dicho proyecto y la manera como se afecta su identidad étnica, cultural, social y económica.

[v] Que se incluyan temas como la prevención de impactos futuros, la mitigación de los que ya se presentaron y los previsibles, la compensación por la pérdida del uso y goce de parte de los terrenos; la participación en los beneficios de la explotación de los recursos naturales. (Corte Constitucional SU-039, 1997, T-652/1998, C-418/2002, C-891/2002, C-030/2008, C-336/2011)

No obstante, la consulta no implica el derecho de los pueblos indígenas y tribales a vetar las medidas legislativas y administrativas que los afectan, sino que busca propiciar un acercamiento y, de ser posible, un acuerdo. Es decir, cuando se trata de planes de desarrollo o de inversión a gran escala, el Estado no debe solo consultar sino también obtener su consentimiento previo, libre e informado.

Conviene advertir que en Colombia los recursos minerales son propiedad del Estado, señalando que estos últimos pertenecen de manera exclusiva a la nación, sin importar su clase, ubicación o estado físico natural y, sobre todo, sin consideración a que la propiedad, posesión o tenencia de los correspondientes terrenos sean de otras entidades públicas, de particulares, de comunidades o grupos (Código de Minas de 2002, articulo 5).

Sin embargo, la regla contenida en el Artículo 332 de la Carta consagra la propiedad del subsuelo y de los recursos naturales no renovables al Estado, pero siempre respetando los derechos adquiridos y perfeccionados con arreglo a las leyes preexistentes, cuya protección encuentra motivo en el mismo canon constitucional en el Artículo 58. Por lo tanto:

[...] los gobiernos deberán establecer o mantener procedimientos con miras a consultar a los pueblos interesados, a fin de determinar si los intereses de 
esos pueblos serían perjudicados, y en qué medida, antes de emprender o autorizar cualquier programa de prospección o explotación de los recursos existentes en sus tierras [...]. (Corte Constitucional C-891 de 2002)

En este sentido, en la explotación y beneficio en la transformación extractiva se hace necesario armonizar dos intereses contrapuestos:

[...] la necesidad de planificar el manejo y aprovechamiento de los recursos naturales en los referidos territorios para garantizar su desarrollo sostenible, su conservación, restauración o sustitución (Art. 80 Const.); y la de asegurar la protección de la integridad étnica, cultural, social y económica de las comunidades indígenas y afrodescendientes [así como campesinos] que ocupan dichos territorios [...]. (Corte Constitucional T-769 de 2009).

Adicionalmente, ponderar la explotación económica de los recursos mineros, la protección del medio ambiente, y garantizar el logro del desarrollo sostenible y la identidad étnica y cultural de las comunidades, se hace vital. Es hoy un debate que no tiene conclusiones precisas, puesto que en los diversos territorios se han realizado consultas populares, donde los departamentos y municipios han excluido prácticas mineras. Tensión compleja entre la facultad de la nación para decidir sobre el subsuelo y la autonomía territorial para atender necesidades de los ciudadanos. En otras palabras, los municipios deben considerar, en los planes de ordenamiento territorial, la consulta popular:

Cuando el desarrollo de proyectos de naturaleza turística, minera o de otro tipo, amenace con crear un cambio significativo en el uso del suelo, que dé lugar a una transformación en las actividades tradicionales de un municipio, se deberá realizar una consulta popular de conformidad con la Ley. La responsabilidad de estas consultas estará a cargo del respectivo municipio. (Ley 136 de 1994, articulo 33)

En definitiva, la nación tiene el deber de concertar con los entes territoriales si la actividad minera amenaza con crear un cambio significativo en el uso del suelo y, por lo tanto, una transformación en la explotación y beneficio extractivos. Aunque no existen reglas concretas en cuanto a la consulta popular, este mecanismo se está empleando para decidir el uso de los suelos, que si bien es un mecanismo legítimo de participación, no puede limitar la administración de los recursos naturales. De esta manera, como lo afirman Pérez, Barreto y Cubides (2017) el medio ambiente debe ser protegido por 
la población en un territorio, pues es su deber preservarlo, y si se llegare a efectuar una perturbación, deben ejecutar los diferentes mecanismos provistos en la Constitución Política para su protección (p.96).

\section{¿Es la acción popular el mecanismo constitucional idóneo?}

La acción popular es un medio constitucional para la protección de los derechos e intereses colectivos. Esta acción se ejerce para evitar daño contingente, es decir, para hacer cesar el riesgo, la amenaza, la vulneración o agravio sobre los derechos fundamentales o intereses colectivos, o con el fin de restituir las cosas a su estado anterior cuando fuere posible (Ley 472 de 1998, artículo 2). En este sentido, se busca la salvaguarda de los derechos que estén relacionados con el patrimonio, el espacio, la seguridad y la salubridad pública, la moral administrativa, el ambiente, la libre competencia económica y otros de similar naturaleza, tal como lo sugiere la carta en el Artículo 88.

En materia de acciones populares podemos encontrar que la Constitución Política de Colombia consagra el deber de actuar conforme al principio de solidaridad, al invocar la protección de derechos que no afectan solo al individuo sino a la comunidad. Por ello, el objetivo de la acción popular no es la entrega de un beneficio económico, sino la defensa de los derechos colectivos que requieran protección inmediata. Es decir, la solidaridad es lo que debe motivar las acciones populares y no la expectativa de esa remuneración (Sentencia C-050, 2012).

En otras palabras, para obtener el amparo de derechos colectivos se debe acudir, cuando fuese posible, a una acción popular:

[Procurando] evitar el daño contingente, hacer cesar el peligro, la amenaza, la vulneración o agravio sobre los derechos colectivos, así como también, desde que sea posible restituir las cosas a su estado anterior cuando fuere posible, máxime cuando dicha acción tiene un carácter preventivo, con el propósito de suprimir la amenaza, o si se causó el daño, tiene un carácter indemnizatorio, a fin de resarcir el daño, esto es, antes de configurarse la vulneración (Sentencia T-022, 2012).

Son tres, de esta manera, los elementos que identifican y definen a la acción popular: 
i) La legitimación, pues es una acción pública a la que puede acceder cualquier persona natural o jurídica para la defensa de derechos que, aunque no le pertenecen en forma específica al demandante, su vulneración o amenaza le afecta $[\ldots]$

ii) Su objeto, en tanto que no fue diseñada para la protección de derechos subjetivos o intereses puramente particulares, sino para la prevención o eliminación de factores dañinos con incidencia colectiva, aunque en su salvaguarda indudablemente puedan protegerse derechos individuales [...]

iii) La cosa juzgada, como quiera que los efectos del fallo que resuelve la controversia desbordan a las partes y resulta exigible respecto del público en general, salvo que aparezcan nuevas pruebas con posterioridad al fallo [...]. (Sentencia T-906, 2012).

Se precisa enunciar por qué la jurisprudencia constitucional de Colombia ha reconocido la procedencia de la acción popular y más cuando la afectación recae sobre un derecho colectivo $\mathrm{y}$, al mismo tiempo, puede conllevar a la vulneración o amenaza de derechos fundamentales. A modo de ejemplo conviene señalar cuatro requisitos, los cuales permiten reconocer las violaciones derechos fundamentales y pueden ser revindicados por medio de este mecanismo constitucional:

i) Exista conexidad entre la vulneración de un derecho colectivo y la violación o amenaza a un derecho fundamental, de tal suerte que el daño o la amenaza del derecho fundamental sea "consecuencia inmediata y directa de la perturbación del derecho colectivo".

ii) El peticionario debe ser la persona directa o realmente afectada en su derecho fundamental, pues la acción es de naturaleza subjetiva.

iii) La vulneración o la amenaza del derecho fundamental no deben ser hipotéticas, sino que deben aparecer expresamente probadas.

iv) La orden judicial que se efectué debe buscar el restablecimiento del derecho fundamental afectado, y "no del derecho colectivo en sí mismo considerado, pese a que con su decisión resulte protegido, igualmente, un derecho de esta naturaleza (Sentencia T-710, 2008; Sentencia T-1085, 2012).

Para concluir, la explotación y beneficio extractivos de los recursos naturales deben hacerse compatibles con la protección que el Estado debe proporcionarles a las comunidades, dado que, a pesar de existir mecanismos constitucionales idóneos para salvaguardar la integridad social, cultural y económica en cuanto a derechos colectivos, estos están siendo tutelados 
efectivamente en relación con derechos fundamentales por estar ligados al grupo humano a través de otros mecanismo legales.

\section{Conclusión}

A pesar de los avances normativos y jurisprudenciales logrados en el SIDH, el principal mecanismo de protección para la defensa de los derechos en la explotación de recursos naturales debería ser la consulta previa y el consentimiento, sin embargo, en Colombia, son dos los mecanismos usados tradicionalmente; el primero, la acción pública de inconstitucionalidad, a través de la cual se puede solicitar a la Corte Constitucional que declare la inconstitucionalidad de una ley. Y el segundo, la acción de tutela que, aunque generalmente está disponible para la protección de derechos individuales y fundamentales, puede ser invocada por las comunidades para la protección de sus derechos culturales y territoriales como derechos fundamentales colectivos.

Particularmente, el marco normativo y las reglas jurisprudenciales fijas por la Corte Constitucional en el tema de los recursos naturales, no han sido suficientemente asimiladas por parte de las autoridades estatales encargadas de llevar a cabo los procesos de consulta previa, lo que determina que estos sigan sin cumplir de manera adecuada con los estándares constitucionales e internacionales, además de desconocer otras mecanismos de este orden que son idóneos para este fin, como lo es la acción popular.

Es decir, la consulta previa, el consentimiento, la consulta popular, todos ellos no implican el derecho de los pueblos indígenas, tribales, campesinos y particulares a vetar las medidas legislativas y administrativas que los afectan, sino que busca propiciar un acercamiento con el Estado y, cuando fuera posible, un acuerdo. De ahí la necesidad de planificar el manejo y aprovechamiento de los recursos naturales, pues solo ello permite asegurar la protección e integridad étnica, cultural, social y económica de las comunidades. Pues si bien son mecanismos legítimos de participación, no pueden limitar la administración de los recursos naturales.

Adicionalmente, siguen existiendo problemas estructurales para la protección del medio ambiente, entre los que se destacan serias 
dificultades relacionadas con los múltiples impactos negativos derivados de la implementación de proyectos extractivos, el otorgamiento de licencias ambientales, solicitudes y titulación inconclusas, negación de acceso a la información para las comunidades, entre otros.

En otras palabras, la prospección, la exploración, la construcción, la transformación extractiva, así como la explotación y beneficio en tanto se trata de los recursos naturales en territorios protegidos como paramos y áreas protegidas, debe hacerse compatible con la protección que el Estado debe dispensar a la integridad social, cultural y económica de las comunidades. De ahí que los acuerdos o la concertación deben estar desprovistos de arbitrariedad y de autoritarismo; deben ser objetivos, razonables y proporcionales a la finalidad constitucional que exige el Estado.

\section{Referencias bibliográficas}

Comisión Interamericana Derechos Humanos. (2015). Pueblos indígenas, comunidades afrodescendientes y recursos naturales: protección de derechos humanos en el contexto de actividades de extracción, explotación y desarrollo. Recuperado el 18 de mayo febrero de 2019 de:http://www.oas.org/es/cidh/informes/pdfs/ IndustriasExtractivas2016.pdf

(1997). Informe sobre la Situación de los Derechos Humanos en Ecuador. Recuperado el 18 de Mayo de 2018, de http://www.cidh.org/countryrep/ecuadorsp/indice.htm

(2002). Informe 75/02, Caso 11.140, Mary y Carrie Dann, Estados Unidos. Recuperado el 18 de Mayo de 2018, de http://www.cidh.org/annualrep/2002sp/ EEUU.11140c.htm

. Informe 40/04, Fondo, Caso 12.052, Comunidades Indígenas Mayas del Distrito de Toledo, Belice. Recuperado el 18 de Mayo de 2018, de https://www.cidh.oas.org/ annualrep/2004sp/Belize.12053.htm

. (2007). Acceso a la Justicia e Inclusión Social: El Camino hacia el Fortalecimiento de la Democracia en Bolivia. Recuperado el 18 de Mayo de 2018, de http://www.cidh. org/countryrep/Bolivia2007sp/Bolivia07indice.sp.htm

. (2009). Derechos de los pueblos indígenas y tribales sobre sus tierras ancestrales y recursos naturales. Recuperado el 18 de Mayo de 2018, de https://www.oas.org/es/ cidh/indigenas/docs/pdf/tierras-ancestrales.esp.pdf 
Conferencia Especializada Interamericana sobre Derechos Humanos. (1969). Convención Americana de Derechos Humanos. San José de Costa Rica. Recuperado el 18 de mayo febrero de 2019 https://www.oas.org/dil/esp/tratados_b-32_convencion_ americana_sobre_derechos_humanos.htm

Conferencia General de la Organización Internacional del Trabajo. (1989). Convenio 169 de 1989 de la Organización Internacional del Trabajo. Ginebra. Recuperado el 18 de mayo febrero de 2019 https://www.ilo.org/dyn/normlex/es/f?p=NORMLEXPUB:12 100:0::NO::P12100_ILO_CODE:C169

Congreso de la República de Colombia. (27/08/1993) Ley 70 de 1993, por la cual se desarrolla el Artículo transitorio 55 de la Constitución Política. Diario Oficial No. 41.013. Recuperado el 18 de mayo febrero de 2019 http://www.secretariasenado. gov.co/senado/basedoc/ley_0070_1993.html

. (22/12/1993). Ley 99 de 1993, por la cual se crea el Ministerio del Medio Ambiente, se reordena el sector público encargado de la gestión y conservación del medio ambiente y los recursos naturales renovables, se organiza el Sistema Nacional Ambiental, SINA, y se dictan otras disposiciones. Diario Oficial No. 41.146. Recuperado el 18 de mayo febrero de 2019 http://www.secretariasenado. gov.co/senado/basedoc/ley_0099_1993.html

. (2/06/1994). Ley 136 de 1994, por la cual se dictan normas tendientes a modernizar la organización y el funcionamiento de los municipios. Diario Oficial No. 41.377. Recuperado el 18 de mayo febrero de 2019 http://www. secretariasenado.gov.co/senado/basedoc/ley_0136_1994.html

. (6/08/1998). Ley 472 de 1998, por la cual se desarrolla el Artículo 88 de la Constitución Política de Colombia en relación con el ejercicio de las acciones populares y de grupo y se dictan otras disposiciones. Diario Oficial No. 43.357. Recuperado el 18 de mayo febrero de 2019 http://www.secretariasenado.gov.co/ senado/basedoc/ley_0472_1998.html

. (8/09/2001). Ley 685 de 2001, por la cual se expide el Código de Minas y se dictan otras disposiciones. Diario Oficial No. 44.545. Recuperado el 18 de mayo febrero de 2019 http://www.secretariasenado.gov.co/senado/basedoc/ley_0685_2001.html

Constitución Política de Colombia. Publicada en la Gaceta Constitucional No. 116 (20/07/1991). Recuperado el 18 de mayo febrero de 2019 http://www. secretariasenado.gov.co/senado/basedoc/constitucion_politica_1991.html

Corte Interamericana de Derechos Humanos. (28/11/2008). Caso del pueblo Saramaka vs. Surinam. Excepciones Preliminares, Fondo, Reparaciones y Costas. Recuperado el 18 de mayo febrero de 2019 http://www.corteidh.or.cr/docs/casos/articulos/ seriec_172_esp.pdf 
(27/06/2012). Caso pueblo indígena Kichwa de Sarayaku vs. Ecuador. Fondo, reparaciones. Recuperado el 18 de mayo febrero de 2019 http://corteidh.or.cr/ docs/casos/articulos/seriec_245_esp.pdf

. (24/08/2010). Caso comunidad indígena Xákmok Kásek vs. Paraguay. Fondo, reparaciones y costas. Recuperado el 18 de mayo febrero de 2019 http://www. corteidh.or.cr/docs/casos/articulos/seriec_214_esp.pdf

(17/06/2005). Caso comunidad indígena Yakye Axa vs. Paraguay. Fondo, reparaciones y costas. Recuperado el 18 de mayo febrero de 2019 http://www. corteidh.or.cr/docs/casos/articulos/seriec_125_esp.pdf

. (31/08/2001). Caso de la comunidad Mayagna (Sumo) Awas Tingni vs. Nicaragua. Fondo, reparaciones y costas. Recuperado el 18 de mayo febrero de 2019 http:// www.corteidh.or.cr/docs/casos/articulos/Seriec_79_esp.pdf

. (23/06/2005). Caso Yatama vs. Nicaragua. Excepciones preliminares. Fondo, reparaciones y costas. Recuperado el 18 de mayo febrero de 2019 http://www. corteidh.or.cr/docs/casos/articulos/seriec_127_esp.pdf

. (1/07/2006). Caso de las masacres de Ituango vs. Colombia. Excepciones preliminares. Fondo, reparaciones y costas. Recuperado el 18 de mayo febrero de 2019 http:// www.corteidh.or.cr/docs/casos/articulos/seriec_148_esp.pdf

Cubides, J., y Martínez, A. (2015). Influencia de la Corte Interamericana de los Derechos Humanos y del Control de Convencionalidad (CCV): análisis de dos casos paradigmáticos. En N. Chacón., J. Cubides., L. Díaz., A. Martínez., D. Vargas., y T. Vivas. Eficacia del Sistema Interamericano de Derechos Humanos. (pp-95-123). Bogotá: Universidad Católica de Colombia.

Cubides, J., \&Vivas, T. (2012). Diálogo judicial transnacional en la implementación de las sentencias de la Corte Interamericana. Entramado, 8(2). pp. 184-204. Universidad Libre. Cali, Colombia.

.Cubides, J., y Martínez, A. (2015). Influencia de la Corte Interamericana de los Derechos Humanos y del Control de Convencionalidad (CCV): Análisis de dos casos paradigmáticos. En N. Chacon., J. Cubides., L. Diaz., A. Martínez., D. Vargas., y T. Vivas. Eficacia del Sistema Interamericano de Derechos Humanos. (pp-95-123). Colección IUS Público. Universidad Católica de Colombia, Bogotá.

Fundación para el Debido Proceso \& Oxfam. (Ed.). (2015). El derecho a la consulta y al consentimiento previo, libre e informado en América Latina. Avances y desafíos para su implementación Bolivia, Brasil, Chile, Colombia, Guatemala y Perú. Washington, D.C.: Fundación para el Debido Proceso. 
(2011). El derecho a la consulta previa, libre e informada de los pueblos indígenas. La situación de Bolivia, Colombia, Ecuador y Perú. Washington, D.C.: Fundación para el Debido Proceso.

Galvis, M. \& Ramírez, Á. (2013). Digesto de jurisprudencia latinoamericana sobre los derechos de los pueblos indígenas a la participación, la consulta previa y la propiedad comunitaria. Washington, D.C.: Fundación para el Debido Proceso.

Presidencia de la Republica. (7/09/1998). Decreto 2001 de 1998, por el cual se reglamenta el inciso final del Artículo 29, el inciso 3o. y el parágrafo 1o. del Artículo 94 de la Ley 135 de 1961 en lo relativo a la constitución de resguardos indígenas en el territorio nacional. Diario Oficial No. 43.380. Recuperado el 18 de mayo febrero de 2019 http://www.secretariasenado.gov.co/senado/basedoc/decreto_1818_1998.html

. (8/08/1996). Decreto 1397 de 1996, por el cual se crea la Comisión Nacional de Territorios Indígenas y la Mesa Permanente de Concertación con los pueblos y organizaciones indígenas y se dictan otras disposiciones. Diario Oficial No. 42853. Recuperado el 18 de mayo febrero de 2019 http://www.suin-juriscol.gov.co/ viewDocument.asp?ruta $=$ Decretos $/ 1279607$

. (15/07/1998) Decreto 1320 de 1998, por el cual se reglamenta la consulta previa con las comunidades indígenas y negras para la explotación de los recursos naturales dentro de su territorio. Diario Oficial No 43.340. Recuperado el 18 de mayo febrero de 2019 https://www.mininterior.gov.co/sites/default/files/co-decreto-1320-98consulta-previa-indigenas-_2.pdf

(26/03/2010). Directiva presidencial 001 de 2010, garantía del derecho a la consulta previa de los grupos étnicos nacionales. Recuperado el 18 de mayo febrero de 2019 https://www.mininterior.gov.co/sites/default/files/13_directiva_presidencial_01_ de_2010.pdf

- (11/08/2011). Decreto 2893 de 2011, por el cual se modifican los objetivos, la estructura orgánica y funciones del Ministerio del Interior y se integra el Sector Administrativo del Interior. Diario Oficial No. 48.158. Recuperado el 18 de mayo febrero de 2019 http://www.secretariasenado.gov.co/senado/basedoc/ decreto_2893_2011.html

. (20/11/2013). Decreto 2613 de 2013, por el cual se adopta el protocolo de coordinación interinstitucional para la consulta previa. Recuperado el 18 de mayo febrero de 2019 https://www.mininterior.gov.co/sites/default/files/11_ decreto_2613_de_2013.pdf

(07/11/2013). Directiva presidencial 10 de 2013, guía para la realización de la consulta previa. Recuperado el 18 de mayo febrero de 2019 https://www. mininterior.gov.co/sites/default/files/12_directiva_presidencial_ndeg_10_del_07_ de_noviembre_2013_4.pdf 
Slack, k. (2011). Derechos humanos e industrias extractivas en América Latina. Empresas y derechos humanos: una relación compleja. Revista de la Fundación para el Debido Proceso. - (15), 4-6.

Corte Constitucional. (1998). Sentencia de unificación 510 con ponencia del magistrado Eduardo Cifuentes Muñoz. (2010). Sentencia de tutela 617 con ponencia del magistrado Luis Ernesto Vargas Silva.

(2011). Sentencia de tutela 235 con ponencia del magistrado Luis Ernesto Vargas Silva.

. (2005). Sentencia de constitucional 180 con ponencia del magistrado Humberto Antonio Sierra Porto.

. (2011). Sentencia de tutela 129 con ponencia del magistrado Jorge Iván Palacio Palacio.

- (1997). Sentencia de unificación 039 con ponencia del magistrado Antonio Barrera Carbonell.

. (1998). Sentencia de tutela 652 con ponencia del magistrado Carlos Gaviria Díaz.

. (2002). Sentencia de constitucional 418 con ponencia del magistrado Álvaro Tafur Galvis.

. (2002). Sentencia de constitucional 891 con ponencia del magistrado Jaime Araujo Rentería.

- (2008). Sentencia de constitucional 030 con ponencia del magistrado Rodrigo Escobar Gil.

. (2011). Sentencia de constitucional 336 con ponencia del magistrado Jorge Ignacio Pretelt Chaljub.

. (2012). Sentencia de constitucional 050 con ponencia del magistrado Luis Ernesto Vargas Silva.

(2012). Sentencia de tutela 022 con ponencia del magistrado Gabriel Eduardo Mendoza Martelo.

. (2012). Sentencia de tutela 906 con ponencia del magistrado Jorge Ignacio Pretelt Chaljub.

. (2012). Sentencia de tutela 1085 con ponencia del magistrado Jorge Ignacio Pretelt Chaljub. 
(2008). Sentencia de tutela 710 con ponencia del magistrado Jaime Córdoba Triviño.

. (2002). Sentencia de constitucionalidad 891 con ponencia del magistrado Jaime Araujo Rentería.

. (2009). Sentencia de tutela 769 con ponencia del magistrado Nilson Pinilla Pinilla.

Vallejo, H., \& Cubides, J. (Ed). (2017). El conflicto armado interno en Colombia: análisis jurídico de protección a las víctimas y del medio ambiente. Bogotá: Editorial Escuela Superior de Guerra. 